\title{
THE SUBSTANCE CAUSING RENAL HYPERTENSION
}

By E. BRAUN-MENENDEZ, J. C. FASCIOLO, L. F. LELOIR AND J. M. MUÑOZ

Instituto de Fisiología, Facultad de Medicina, Buenos Aires

(Received 13 February 1940)

Goldblatt, Lynch, Hanzal \& Summerville [1934] have shown that chronic arterial hypertension can be produced by permanent compression of the renal artery. If the ischaemic kidney is extirpated or the arterial compression discontinued, the blood pressure returns to the normal level [Goldblatt et al. 1934; Dicker, 1937; Houssay \& Fasciolo, 1937 a; Goldblatt, 1937; etc.].

Houssay \& Fasciolo [1937b] grafted the ischaemic kidneys of dogs with chronic hypertension into the neck of normal or nephrectomized dogs. An immediate increase in blood pressure of $30-70 \mathrm{~mm}$. $\mathrm{Hg}$ was observed, whereas no appreciable change was produced by grafting normal kidneys. Bouckaert, Grimson \& Heymans [1939] have confirmed the findings which clearly demonstrate that ischaemic kidneys produce a pressor substance.

With a different technique Houssay \& Taquini [1938a] have studied the appearance of the active principle. Venous blood of ischaemic or normal kidneys was collected in a "cava pocket", diluted with citrate and Ringer solution and then tested on the Läwen-Trendelenburg preparation. The citrated plasma of the venous blood of ischaemic kidneys was found to produce vasoconstriction [Fasciolo, Houssay \& Taquini, 1938].

Pressor or vasoconstrictor properties of the renal venous blood appear not only in chronic ischaemia of the kidney, but can also be detected a few minutes after the compression of the artery of a normal kidney [Enger, Linder \& Sarre, 1938; Verney \& Vogt, 1938a; Grimson, 1939; Braun-Menendez \& Fasciolo, 1939]. We have repeated and confirmed some of the experiments on the pressor and vasoconstrictor properties of the blood from ischaemic kidneys and studied some of the properties of the active substance of this blood. This substance was found to be different 
from the pressor kidney protein "renin" which has been studied by Tigerstedt [1897], Hessel [1938], Pickering \& Prinzmetal [1938], Helmer \& Page [1939], Swingle, Taylor, Collings \& Ways [1939], etc. But it was found that by the action of renin on blood proteins a substance is formed which has the same chemical and physiological properties as the pressor substance from the venous blood of ischaemic kidneys. This substance was named "hypertensin" [Braun-Menendeż, Fasciolo, Leloir \& Muñoz, 1939; Muñoz, Braun-Menendez, Fasciolo \& Leloir, 1939].

\section{A. Properties of the venous blood of KIDNEYS WITH ACUTE ISCHAEMIA}

(1) Pressor action

(a) Experiments with a kidney grafted into the neck of a normal dog. When a normal kidney was grafted into the neck of a normal or nephrectomized dog, no changes of blood pressure occurred. But if the renal artery of the graft was partially compressed, an increase in blood pressure was produced (about $30 \mathrm{~mm}$. $\mathrm{Hg}$ in 5-6 min.). With a previous ischaemia of 60-90 min. the effect of the graft was greater.

In order to study the pressor properties of the venous blood of these ischaemic kidneys, experiments were carried out as follows. The renal artery of a normal dog under chloralose anaesthesia was compressed. After 40-80 min. the kidney was removed and the renal artery connected to the carotid of a second dog. This second dog was previously treated with chloralose and an anticoagulant (chlorazol fast pink, $0.08 \mathrm{~g} . / \mathrm{kg}$. body weight). The venous blood of the grafted kidney was then collected. The first 20 c.c. were discarded and the next portion $(100$ c.c.) flowing at a rate of 10-15 c.c./min. was kept for the test. Blood from the jugular vein or from the vein of normal kidney was used as control. When the blood pressure of the second dog was quite steady, the blood samples were slowly (1-2 min.) injected into the jugular vein.

Experiments carried out in this manner showed that the blood of the ischaemic kidney always produced greater increases in blood pressure than the control blood (Table I).

TABLE I. The action of venous blood of kidneys grafted into the neck

\begin{tabular}{|c|c|c|c|c|c|c|c|c|}
\hline \multirow[b]{2}{*}{$\begin{array}{l}\text { Venous blood of } \\
\text { ischaemic kidney }\end{array}$} & \multicolumn{7}{|c|}{$\begin{array}{l}\text { Rise in blood pressure }(\mathrm{mm} . \mathrm{Hg}) \text { by } \\
\text { injection of } 20 \text { c.c. of plasma }\end{array}$} & \multirow{2}{*}{$\begin{array}{c}\text { Averag } \\
28.8\end{array}$} \\
\hline & 32 & 28 & 17 & 16 & 70 & 23 & 16 & \\
\hline Control blood & 16 & 18 & 10 & 10 & 20 & 10 & 10 & $13 \cdot 2$ \\
\hline
\end{tabular}


The compression of other arteries (femoral, duodenal) did not confer pressor properties on the corresponding venous blood.

(b) Experiments with Starling's heart-lung preparation. The technique was as follows: The heart-lung preparation was prepared in the classical manner using a reservoir of 1500 c.c. Defibrinated blood was circulated for 90-120 min., a time which, as we have found, is sufficient for the disappearance of its vasoconstrictor action [Braun-Menendez \& Fasciolo, 1939]. The left kidney of a large dog (15-18 kg.) was then extirpated and

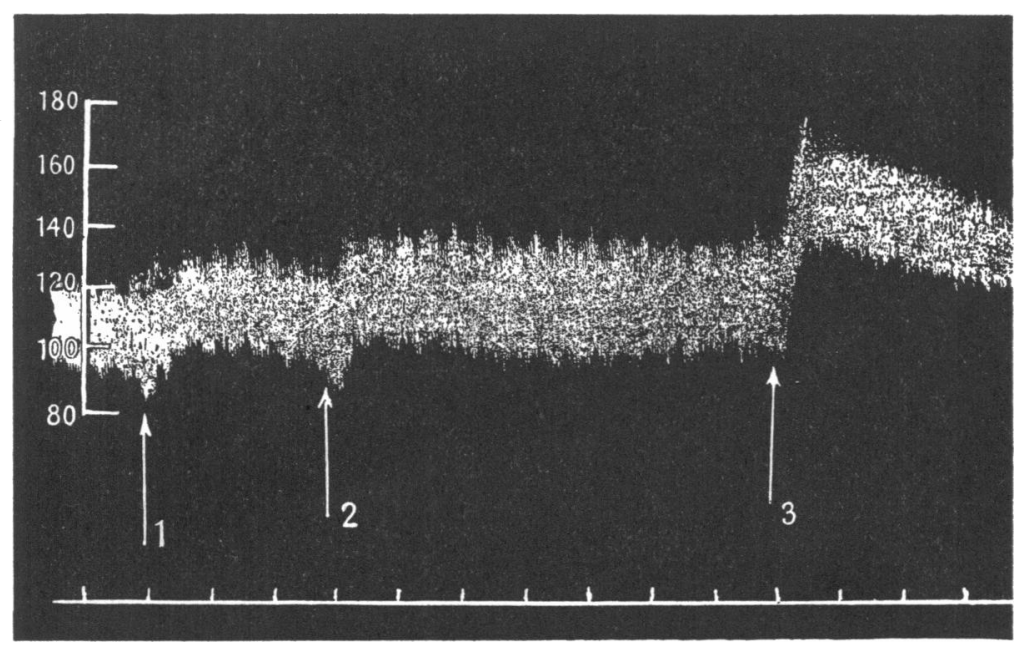

Fig. 1. The pressor action of blood from ischaemic kidney. Dog, $14 \mathrm{~kg}$., chloralosed and nephrectomized. Femoral blood pressure $(\mathrm{mm} . \mathrm{Hg})$. Time in minutes. 1, intravenous injection of 15 c.c. serum of circuit's blood; 2,15 c.c. serum of circuit's blood after $10 \mathrm{~min}$. asphyxia of the heart-lung preparation; 3,15 c.c. serum of venous blood of perfused ischaemic kidney.

rapidly grafted to the arterial side of the heart-lung preparation following Verney \& Starling's [1922] technique. The venous inflow and arterial pressure of the preparation were then regulated so that the flow through the kidney was from 100 to 250 c.c./min. according to its size. These conditions were maintained for 5 or 10 min., the kidney's venous blood being returned to the circuit. After this time, samples of venous blood were collected and then ischaemia was produced by decreasing the venous inflow to the heart and the arterial pressure, or, if necessary, by compressing the tube leading to the renal artery. The renal blood flow was reduced to $10-20 \%$ of the original value. The samples of venous blood of ischaemic kidney and in many cases control samples of blood from the 
circuit were then collected, the blood was centrifuged and the serum, 10-20 c.c., was injected intravenously into chloralosed dogs which 1 or $2 \mathrm{hr}$. before had been injected with 5-10 c.c. of blood from the circuit. In this manner the shock that the injection of the serum samples would otherwise produce was avoided.

The results are shown in Table II.

TABLE II. The action of venous blood of kidneys perfused by the heart-lung preparation

Rise in blood pressure (mm. Hg) per 20 c.c. serum injected

Venous blood of ischaemic kidney

Venous blood of normal kidney

$\begin{array}{llllllllllllllllllllll}28 & 31 & 17 & 42 & 70 & 32 & 30 & 40 & 13 & 25 & 30 & 22 & 40 & 12 & 18 & 37 & 53 & 53 & 53 & 30 & 25 & 33 \cdot 3 \\ 8 & 10 & 20 & . & 16 & 12 & . & . & 13 & . & 0 & . & . & . & . & . & . & 27 & . & . & . & 12 \cdot 3 \\ . & . & . & 12 & 14 & 12 & 13 & 26 & 13 & 5 & 0 & 10 & 20 & 0 & 20 & 22 & 30 & . & 30 & 10 & 25 & 15 \cdot 5\end{array}$

The pressor action of the serum of ischaemic kidneys was rather prolonged (Fig. 1) and was not greatly modified by previous section of the vagi, denervation of the carotid sinus, adrenalectomy or injection of atropine (1 mg./kg.), cocaine (10 mg./kg.), or Fourneau 933 (10 mg./kg.).

\section{(2) Vasoconstrictor action}

(a) Experiments with kidneys grafted into the neck of normal dogs. Following exactly Houssay \& Taquini's [1938 $a, b]$, procedure with the LäwenTrendelenburg preparation, it was found that the citrated plasma of the kidney's venous blood did not produce a vasoconstriction when the flow was normal. But after a few minutes of arterial constriction there was a clear effect which disappeared after the constriction was discontinued.

However, this procedure is not quite free from errors, because by coagulation the blood acquires a strong vasoconstrictor action. The blood of ischaemic kidney is collected more slowly and therefore is more liable to coagulate. Even normal samples of blood collected in oxalate or citrate solution may produce vasoconstriction, although coagulation is hardly detectable. It was in order to eliminate this source of error that we used Starling's heart-lung preparation as a perfusion system for the kidney.

(b) Experiments with the heart-lung preparation. If defibrinated blood is circulated for 30-60 min. through Starling's heart-lung preparation its vasoconstrictor action on the Läwen-Trendelenburg preparation disappears [Braun-Menendez \& Fasciolo, 1939].

The samples of serum were mixed with 7 vol. of Ringer solution and perfused through the Läwen-Trendelenburg preparation. The serum obtained under the described conditions, from the blood of normal kidneys 
with normal blood flow, had no action, whereas that from the same kidney after 10-20 min. ischaemia produced an intense vasoconstriction.

These results agree with those of Houssay \& Taquini [1938 a,b]. Verney \& Vogt [1938b] observed a fall in blood-flow through the gut when a normal isolated kidney perfused by one heart-lung circuit was switched to another by which an excised loop of gut was being perfused.

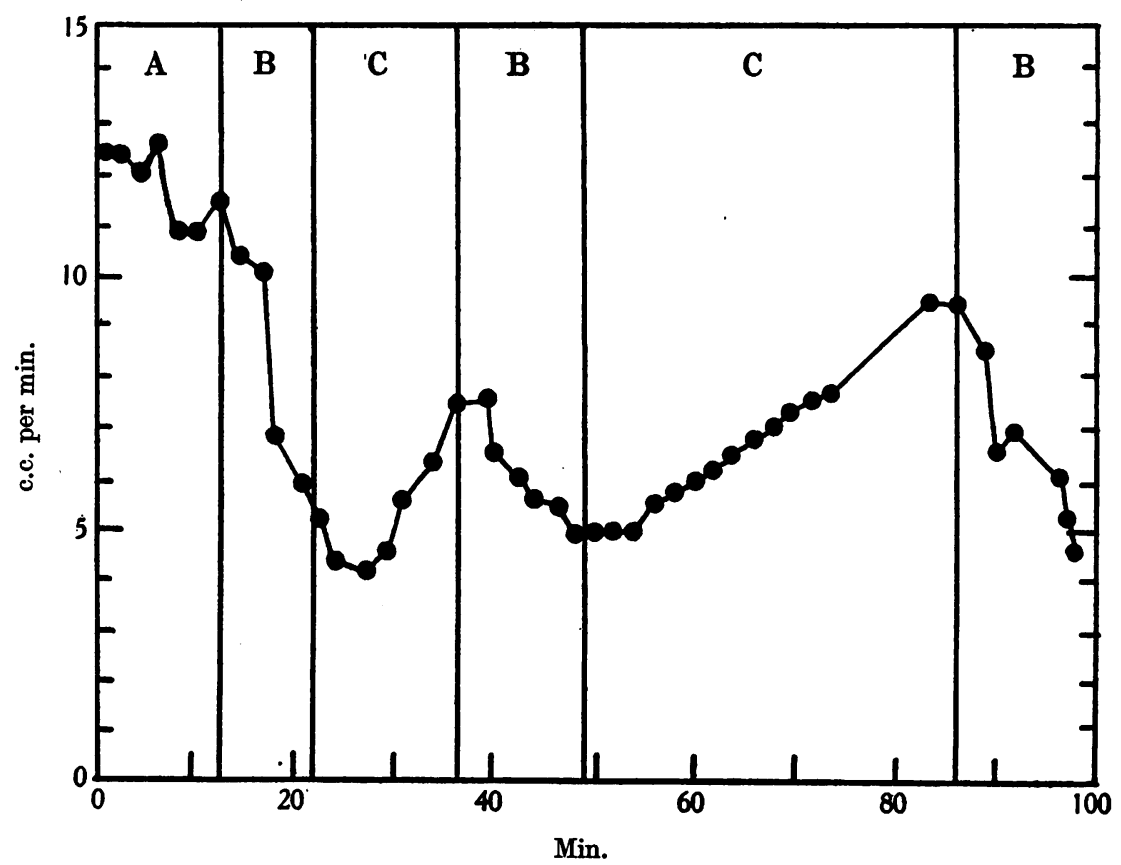

Fig. 2. The vasoconstrictor action of blood from the ischaemic kidney. Perfusion of the denervated leg of a dog with defibrinated blood: A, blood from the heart-lung circuit after functioning $1 \mathrm{hr}$.; B, venous blood of ischaemic kidney; C, venous blood of kidney with normal flow.

In three experiments the vasoconstrictor (Läwen-Trendelenburg preparation) and the pressor action of different samples of blood were compared. It was found that both actions were parallel.

A few perfusions of the denervated dog's leg with defibrinated blood disclosed a marked vasoconstrictor action of the venous blood of ischaemic kidney. The decrease in venous flow was taken as a measure of vasoconstrictor action (Fig. 2). 


\section{(3) Other properties}

The usual plethysmographic methods did not reveal contraction of the leg or kidney or any alterations in the motility of the intestine. But it was found that the injection of blood from the ischaemic kidney produced a net decrease in the volume of the denervated spleen.

No effect was observed on the denervated dog's heart (heart-lung preparation).

\section{B. The PRESSOR SUBSTANCE FROM THE BLOOD OF THE ISCHAEMIC KIDNEY}

\section{(1) Preparation of extracts}

Blood with pressor properties was obtained, as previously described, and centrifuged. The plasma or serum was then precipitated with 3 vol. of acetone. The filtrate was freed from acetone by distillation under reduced pressure and thoroughly extracted with ether, after making alkaline to phenolphthalein and then acid to congo red. After neutralization and, if necessary, filtration, the solution was ready for injection.

\section{(2) Chemical and physiological properties}

Extracts of nineteen different samples of blood of ischaemic kidneys were injected intravenously into nineteen chloralosed dogs. In each case a control extract was prepared with blood from the carotid artery or the jugular vein or from the renal vein of non-ischaemic kidneys.

The extracts from ischaemic kidney blood always produced a bloodpressure increase lasting 3-4 min. (Fig. 3), whereas the controls only produced it in four samples out of nineteen (Table III).

TABLE III. Rise in blood pressure $(\mathrm{mm} . \mathrm{Hg}$ ) after injection of acetone extracts of 50 c.c. serum

\begin{tabular}{|c|c|c|c|c|c|c|c|c|c|c|c|c|c|c|c|c|c|}
\hline \multirow[b]{2}{*}{$\begin{array}{l}\text { Venous blood of } \\
\text { ischaemic kidneys }\end{array}$} & \multicolumn{6}{|c|}{$\begin{array}{l}\text { Ischaemic kidneys grafted into } \\
\text { the neck of normal dogs }\end{array}$} & \multicolumn{11}{|c|}{$\begin{array}{l}\text { Ischaemic kidneys perfused by } \\
\text { a heart-lung preparation }\end{array}$} \\
\hline & 60 & 40 & 54 & 38 & 62 & 16 & 20 & 46 & 22 & 2030 & 20 & 20 & 25 & 30 & 35 & 15 & \\
\hline Control blood & 20 & 0 & 40 & 10 & 0 & 0 & 6 & 0 & 0 & 0 & 0 & 0 & . & 0 & . & . & • \\
\hline
\end{tabular}

As large amounts of venous blood of ischaemic kidneys are difficult to obtain, only a few of the properties of the pressor substance were studied. These properties were found to be the same as those of the substance formed in vitro which are described later.

The pressor effect was not modified if the dogs were previously treated with Fourneau 933 (Fig. 4). After the substance was subjected to $N \mathrm{HCl}$ at $100^{\circ} \mathrm{C}$. for $2 \mathrm{hr}$., no great decrease in activity occurred. The substance 
is insoluble in ether or amyl alcohol, soluble in water, $96 \%$ alcohol and glacial acetic acid and may be kept unaltered for long periods in solution or dried.

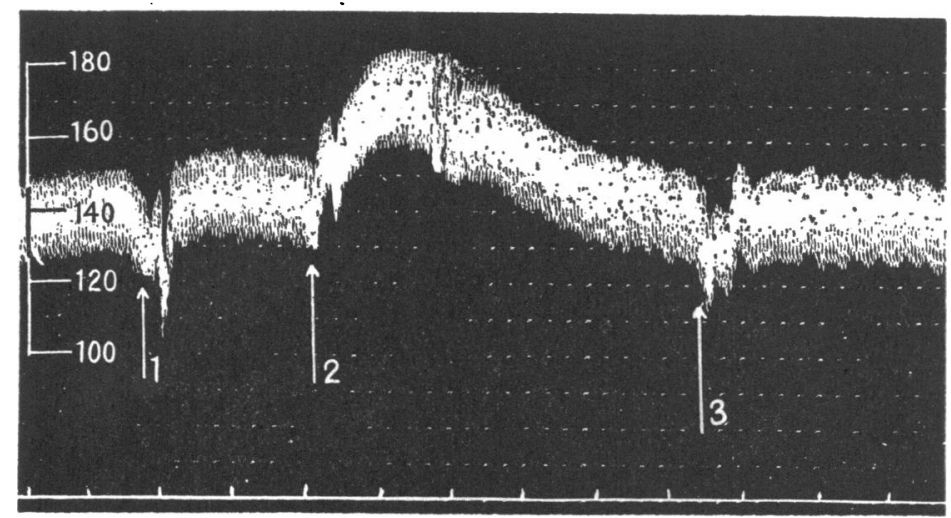

Fig. 3. The pressor action of extracts from the blood of ischaemic kidneys. Dog, $6 \mathrm{~kg}$., chloralosed. Double vagotomy and artificial respiration. Femoral pressure in $\mathrm{mm}$. $\mathrm{Hg}$. Time in minutes. Intravenous injection of acetone extracts of 50 c.c. serum: 1, of circuit's blood $1 \mathrm{hr}$. after completion of the heart-lung preparation; 2 , of venous blood of perfused ischaemic kidney; 3 , of circuit's blood $3 \mathrm{hr}$. after completion of preparation.

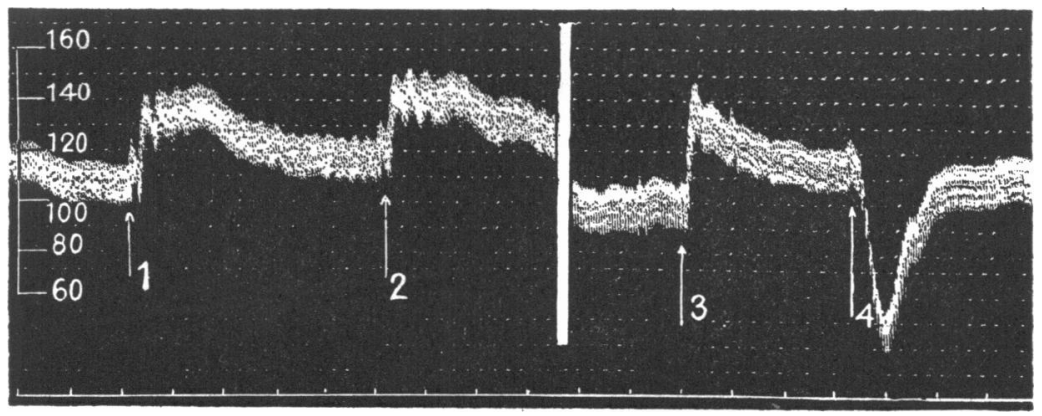

Fig. 4. Effect of Fourneau 933 on the pressor action of blood extracts. Dog, $8 \mathrm{~kg}$., chloralosed and nephrectomized. Double vagotomy and artificial respiration. Femoral pressure in $\mathrm{mm}$. Hg. Time in minutes. Between 2 and 3, intravenous injection of $80 \mathrm{mg}$. of Fourneau 933. 1, intravenous injection of a.cetone extract of 50 c.c. serum from venous blood of ischaemic kidney; 2 , the same after $10 \mathrm{~min}$. at $100^{\circ} \mathrm{C}$. at $p \mathrm{H} 2$; 3 , the same; $4,10 \mu \mathrm{g}$. adrenaline.

The acetone precipitate of serum, after being washed with acetone and ether, dried and dissolved in $1 \% \mathrm{NaCl}$ solution, was also tested. It generally produced a decrease in blood pressure. 


\section{The PRESSOR SUBSTANCE FORMED IN VITRO}

If blood serum is incubated at $37^{\circ} \mathrm{C}$. with renin, a pressor substance is formed which is apparently the same as that which was found in the blood of ischaemic kidneys.

A typical experiment is shown in Fig. 5.

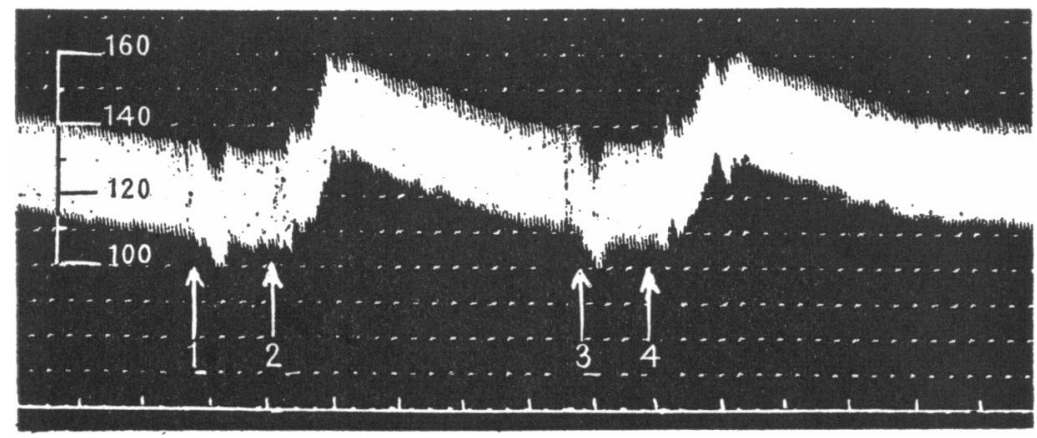

Fig. 5. Formation of hypertensin in vitro. Dog, $12 \mathrm{~kg}$., chloralosed. Both vagi cut. Artificial respiration. Femoral blood pressure in $\mathrm{mm}$. $\mathrm{Hg}$. Time in minutes. 1,20 c.c. of horse serum and 0.5 c.c. renin solution incubated separately and mixed during precipitation with alcohol; 2, the same incubated together $15 \mathrm{~min}$. at $37^{\circ} \mathrm{C}$. and then precipitated; 3, same as 1 but with bovine serum; 4, same as 2 but with bovine serum.

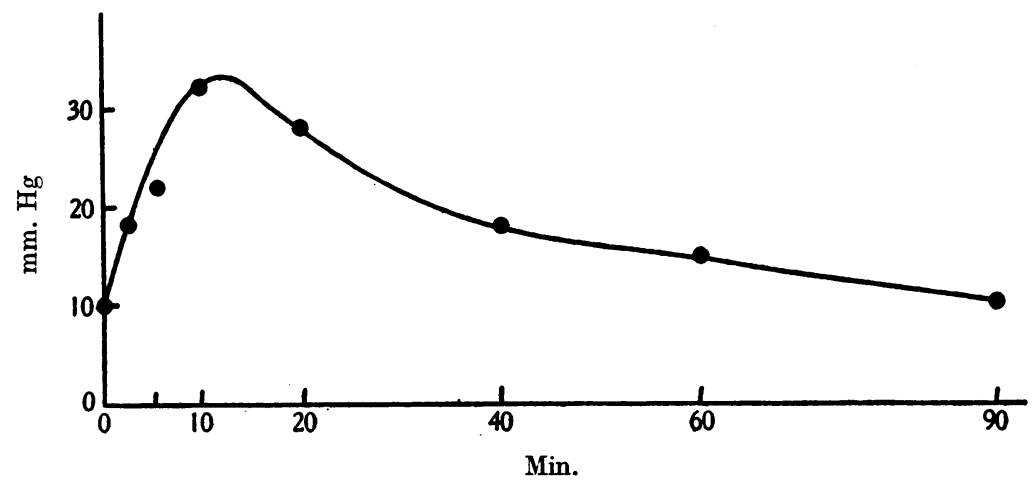

Fig. 6. Blood-pressure increases produced by acetone extracts from 10 c.c. of blood globulins ( $=20$ c.c. serum) incubated at $37^{\circ} \mathrm{C}$. with 0.25 c.c. renin $(=1 \mathrm{~g}$. fresh kidney) for various times.

The same results were obtained with bovine, horse and dog serum. The necessary component was found to be a blood protein (pseudoglobulin) which is precipitated by half-saturation with ammonium 
sulphate and not by dialysis. Haemoglobin, casein, milk serum, and egg or blood albumin were tested with negative results.

The time of reaction with the renin and its concentration have a great importance on the amount of pressor substance obtained. The effect of time is shown in Fig. 6. The formation is rapid and there is afterwards a gradual disappearance of the pressor principle. If the amount of renin is increased the amount of pressor substance is not greater but smaller, whereas with a constant amount of renin more substance is formed if the amount of blood globulins be increased.

By incubation of blood globulins with renin which had been heated for $5 \mathrm{~min}$. at $100^{\circ} \mathrm{C}$. no active extracts were obtained. Many experiments were carried out using pepsin, trypsin or papain or extracts of liver and spleen instead of renin. With none of them was a clear formation of pressor substance obtained.

The $p \mathrm{H}$ optimum is difficult to ascertain. By taking several points in the time curve (Fig. 6) with small amounts of renin, it was found that the formation of hypertensin is faster at a $p \mathrm{H}$ around 7 .

The amount of hypertensin obtained from 20 c.c. serum under the best conditions caused a blood-pressure increase of $20-30 \mathrm{~mm}$. $\mathrm{Hg}$ and was considered as one unit.

\section{(1) Larger scale preparation}

Blood globulins. Bovine blood (40 l.) was collected in the slaughterhouse, $0.2 \%$ potassium oxalate being added. After centrifugation, the plasma (about 20 l.) was precipitated with ammonium sulphate (400 g./l.), and filtered first through fluted paper and then through Büchner funnels in order to free it as much as possible from the residual liquid. The cakes were then dialysed overnight in cellophane bags against running water. The globulins (about 10 l.) were then filtered through muslin.

Renin. Pig kidneys were finely minced, 3 vol. of $2 \% \mathrm{NaCl}$ and $5 \%$ toluol were added and left overnight at room temperature. The toluol and fats were then skimmed off and the rest filtered through cloth. Acetic acid $(5 N)$ was added to the filtrate until it gave a green colour with bromcresol-green. After centrifuging the yellow supernatant liquid was precipitated with 380 g./l. ammonium sulphate. After filtering through Büchner funnels the cake was dialysed overnight. The liquid was then filtered: 1 c.c. corresponded to $3-4 \mathrm{~g}$. fresh kidney and when injected intravenously into chloralosed dogs gave a rise in blood pressure of about $50 \mathrm{~mm}$. Hg. 
Hypertensin. The amount of renin which is to be added depends on the activity of the preparation and was ascertained by small scale trials. Generally it was about $1 \%$. The renin was added to the blood globulins previously heated to $37^{\circ} \mathrm{C}$. After $15 \mathrm{~min}$. the liquid was poured into $3 \mathrm{vol}$. of boiling alcohol $(96 \%)$. When the mixture had boiled for several minutes, it was cooled and filtered in vacuo. The filtrate was evaporated to a small volume under reduced pressure. The water solution was then thoroughly extracted with ether and filtered. Three volumes of ethyl alcohol (96\%) were added and the solution left overnight at $4^{\circ} \mathrm{C}$. After filtration, the solution was evaporated under reduced pressure. The turbid aqueous solution contains about 2000 hypertensin units with a dry wt. of about $15 \mathrm{mg} . / \mathrm{unit}$.

\section{(2) Chemical properties}

The substance is very soluble in water and glacial acetic acid, soluble in $96 \%$ alcohol and insoluble in ethyl ether, chloroform and amyl alcohol.

It can be salted out from aqueous solutions by saturating with ammonium sulphate. It dialyses through cellophane and can be precipitated with phosphotungstic acid. In $N \mathrm{HCl}$ at $100^{\circ} \mathrm{C}$. the activity is completely lost after $3 \mathrm{hr}$. In $0.15 \mathrm{~N} \mathrm{NaOH}$ at $100^{\circ} \mathrm{C}$. activity disappears after 10 min. Benzoylation by the Schotten-Baumann method inactivates hypertensin.

A further purification can be obtained by extracting dry preparations with glacial acetic acid and precipitating with ether. This precipitate contains 1 unit in $3 \mathrm{mg}$.

Salts of heavy metal were not found useful in the purification.

\section{(3) The destruction of hypertensin}

Hypertensin is a stable substance, but it is rapidly destroyed by tissue extracts. As shown in Fig. 6 hypertensin disappears after a certain time when the mixture of renin and blood globulins is incubated. If one unit of hypertensin is incubated for $15 \mathrm{~min}$. at $37^{\circ} \mathrm{C}$. with 1 c.c. of renin and afterwards heated for $5 \mathrm{~min}$. at $100^{\circ} \mathrm{C}$. to destroy the renin, no pressor effect is obtained on injection. If renin is boiled before the incubation it has no effect, whereas neither cyanide $M / 200$ nor anaerobic incubation inhibits the destruction.

Extracts of liver and spleen, and commercial trypsin, pepsin and papain solutions were also found to destroy hypertensin.

Blood serum also possesses this action: 2 c.c. of dog's, horse's or bovine serum inactivate hypertensin completely in $40-60 \mathrm{~min}$. at $37^{\circ} \mathrm{C}$., but not 
at $4^{\circ} \mathrm{C}$. The active fraction of blood was found to be precipitated by halfsaturation with ammonium sulphate, but not by dialysis.

Before injecting the hypertensin thus treated, proteins were removed by precipitation with three volumes of alcohol $(96 \%)$ and the latter was evaporated under reduced pressure.

\section{(4) Pharmacological properties}

Hypertensin, prepared as previously described, was used, the aqueous solution being previously neutralized and filtered. One unit was considered as the amount which gave an increase of $20-30 \mathrm{~mm}$. $\mathrm{Hg}$ in blood pressure. The responses of different dogs were somewhat variable.

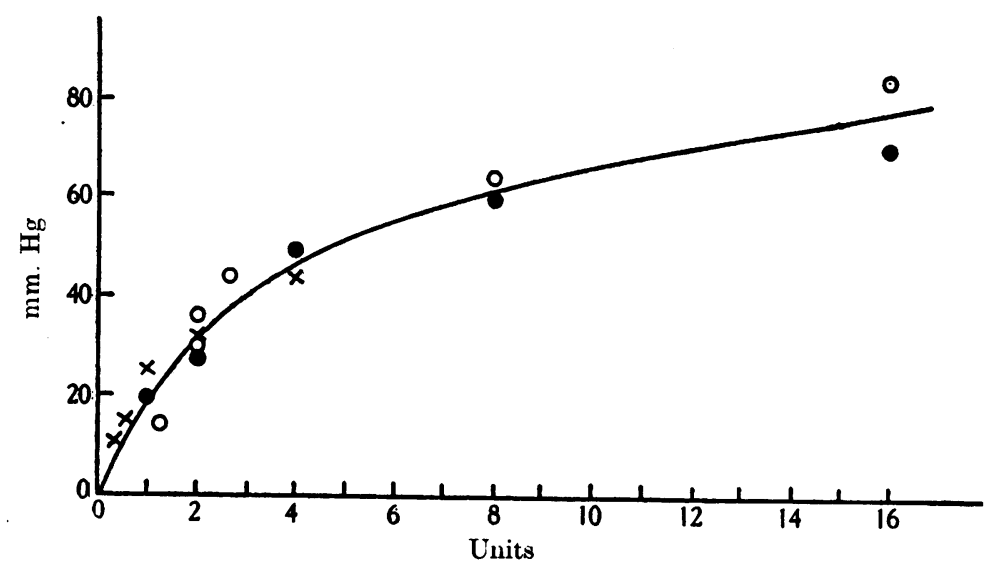

Fig. 7. Increases in blood pressure produced by different amounts of hypertensin.

Response to different doses. The increase in blood pressure, which lasts about 3-4 min., is proportional to the amount injected, as shown in Fig. 7.

Injection into different blood vessels. Pressor effects were obtained when hypertensin was injected into veins (jugular or saphenous) or into arteries (aorta or carotid). The latent period depends on the site of injection, for the injection into the aorta it was 6 sec.; into the jugular vein, 15 sec.; saphenous vein, 18 sec.; carotid artery, 35 sec. These results suggest that the hypertension is due to a vasoconstriction in the largest vascular beds (the splanchnic area and the limbs).

Action on different organs. By the use of plethysmographs it was found that one unit of hypertensin decreases the volume of the spleen and of the kidney. The heart rate was not modified in vagotomized dogs. A small and retarded inhibitory effect on the movements of the intestine in situ 
was found. This effect appeared 1 or $2 \mathrm{~min}$. after the injection into the jugular vein, that is, when the pressor effect had already attained its maximum. Dilute hypertensin ( 1 unit in 200 c.c. Ringer solution) tested on the Läwen-Trendelenburg preparation produced a marked vasoconstriction. No change in frequency or amplitude of contraction of the toad's (Bufo arenarum Hensel) heart was produced even with concentrations of 1 unit in 100 c.c. Ringer solution.

Repeated and continuous injections. It is known that renin, vasopressin, tyramine, "veritol" and many other substances produce a lesser effect, or none at all, after repeated injections, this state being known as

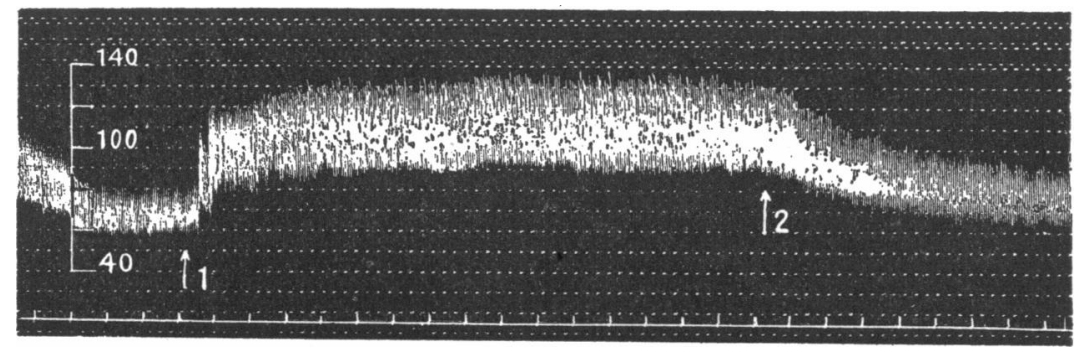

Fig. 8. Continuous intravenous injection of hypertensin. Dog, $6.5 \mathrm{~kg}$., chloralosed. Double vagotomy. Artificial respiration. Femoral blood pressure in $\mathrm{mm}$. Hg. Time in minutes. 1 , intravenous injection of hypertensin is started at a rate of 1 unit/min.; 2, end of injection.

"tachyphylaxis". With hypertensin this does not occur. If the experimental conditions remain constant (blood-pressure level, degree of anaesthesia) the injection of hypertensin always produces exactly the same response for the same dose, even if injections are repeated at short intervals over a long time ( $2 \mathrm{hr}$. or more). Continuous intravenous injection of hypertensin produces an increase in blood pressure which is maintained as long as the injection is continued (Fig. 8).

The pressor effect is not modified by the destruction of the medulla, and the pithed dog has proved to be a good test owing to its low blood pressure and the constancy with which it is maintained. This shows that the action of hypertensin is peripheral and not central. Adrenalectomy does not suppress the pressor effect, although the response was smaller in dogs adrenalectomized $24 \mathrm{hr}$. before. The pressor action of hypertensin is therefore not due to a discharge of adrenaline. In an experiment after adrenojugular anastomosis hypertensin did not produce any appreciable discharge of adrenaline. 
Influence of drugs. The previous injection of Fourneau 933 (10 mg./kg.) does not modify the pressor action of hypertensin, whereas it reverses the action of adrenaline, tyramine and urohypertensin.

The previous injection of cocaine $(10 \mathrm{mg} . / \mathrm{kg}$.$) and "veritol" (50-$ $60 \mu \mathrm{g} . / \mathrm{kg}$.), especially the latter, reinforces the action of hypertensin. Atropine (1 mg. $/ \mathrm{kg}$.) has no action and pyrogallol $(20 \mathrm{mg} . / \mathrm{kg}$.) slightly reinforces the action.

The action of renin. Renin can be easily distinguished from hypertensin by chemical methods, but their pharmacological properties are very similar. Cocaine and Fourneau 933 have the same influence on both. The increase in blood pressure, produced by a single injection of hypertensin, lasts a shorter time than that of renin but, by continuous injection, the pressure curves can be made equal.

Renin diluted with Ringer solution 1 in 50 has no vasoconstrictor action on the Läwen-Trendelenburg preparation. Horse's serum (diluted with Ringer solution 1 in 8 ) also has no action. But if a mixture of both is incubated for about $15 \mathrm{~min}$. at $37^{\circ} \mathrm{C}$. a strong vasoconstrictor effect is observed on perfusion.

The rise in blood pressure due to the injection of renin appears gradually, while that due to hypertensin has a very short latent period.

\section{Discussion}

The substance extracted from the venous blood of ischaemic kidney has the same chemical and pharmacological properties as the substance formed by the interaction of renin and blood globulins, and it can be assumed that it is the same substance, which may be called hypertensin.

We may assume that renin is an enzyme whose substrate is a blood protein belonging to the pseudo-globulin fraction, the reaction product being hypertensin.

Several facts are in favour of this interpretation. Boiled renin does not liberate hypertensin when incubated with blood globulins. If the amount of renin is increased, the yield in hypertensin does not increase but decreases. This is due to the occurrence of two simultaneous reactions: the formation of hypertensin and its disappearance, the latter being produced by renin or by some other enzyme present in the preparations we have used. ${ }^{1}$

If a constant amount of renin is incubated with variable amounts of globulins, the amount of hypertensin formed is roughly proportional to the amount of globulins.

PH. XCVIII.

1 See note at the end of this paper.

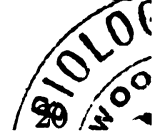


There appears to be a certain specificity for the substrate (blood pseudo-globulins), as no hypertensin is formed if they are replaced by other proteins such as serum, albumin, haemoglobin, or by milk or egg proteins. On the other hand, renin cannot be replaced by other enzymes (pancreatin, pepsin, papain) or extracts of liver or spleen. Proteolytic activity could be revealed in our renin preparations either by the clotting of milk or by Anson's haemoglobin method [1938] as described for cathepsin. Whether renin is the same enzyme as kidney cathepsin is a problem which will require further investigation.

Some of the chemical properties of hypertensin-the insolubility in organic solvents, the inactivation by acids and proteolytic enzymesseem to indicate that it is a polypeptide. It can easily be shown that it is different from vasopressin because it is much more stable towards acids. Its effect appears unchanged when tested on dogs treated with Fourneau 933 which leads to an inversion of the action of tyramine, adrenaline, "veritol" and urohypertensin, which can also be distinguished by chemical methods.

Does renin produce a direct increase in blood pressure, or does it act through the formation of hypertensin? In the Läwen-Trendelenburg preparation, renin has no action provided that the concentration is not too great. Blood globulins alone also have no action, but if they are previously incubated with renin, a strong vasoconstrictor action appears. Similar experiments by perfusion of a dog's tail are reported by Kohlstaedt, Helmer \& Page [1938], their interpretation being that there occurs an activation of renin by blood proteins. The increase in blood pressure produced by renin is more gradual and of longer duration than that which follows a single injection of hypertensin. But it was found that by con-. tinuous injection of hypertensin a curve similar to that of renin was obtained. It is therefore more likely that both vasoconstrictor and pressor actions of renin are due to the formation of hypertensin.

Renin can be extracted from normal kidneys, but little or no hypertensin appears in the venous blood of the normal kidney; but after ischaemia hypertensin is produced and can be shown to exist in the venous blood. This difference may be due either to an activation of the enzyme or to a longer contact between enzyme and substrate.

Renin might be in an inactive state in normal kindey, the activation being produced by ischaemia or during the process of extraction. Reducing agents are known [cf. Bersin, 1935; Hellerman, 1937; etc.] to activate some proteolytic enzymes such as papain and cathepsin, and a process of reduction is quite likely to occur during ischaemia and during the extrac- 
tion of renin. On the other hand, during ischaemia, the time of contact of blood with renin is probably longer and therefore hypertensin might be formed. Still another possibility is that ischaemia produces certain changes in the renal tissue, bringing renin into closer contact with the blood globulins.

\section{SUMmaRY}

The pressor and vasoconstrictor properties of the venous blood from kidneys in acute ischaemia have been studied. Extracts of this blood contain a pressor substance (hypertensin) which is also formed in vitro when blood proteins are incubated with renin.

Some chemical and pharmacological properties of hypertensin have been studied and found to be different from those of other known substances.

Experiments are reported which indicate that renin is an enzyme, blood pseudo-globulins the substrate and hypertensin the reaction product. Hypertensin disappears if the reaction is permitted to go too far and it is also inactivated by other proteolytic enzymes and by blood.

The pressor action of renin appears to be due to the formation of hypertensin in blood and a similar mechanism is suggested for arterial hypertension due to renal ischaemia.

The authors wish to express their thanks to Prof. B. A. Houssay for his helpful advice and criticism, and to C. Chaves and A. Bernardez for their invaluable help.

\section{REFERENCES}

Anson, M. L. [1938]. J. gen. Physiol. 22, 79.

Bersin, T. [1935]. Ergebn. Enzymforsch. 4, 68.

Bouckaert, J. J., Grimson, K. S. \& Heymans, C. [1939]. J. Physiol. 96, 44 P.

Braun-Menendez, E. \& Fasciolo, J. C. [1939]. Rev. Soc. argent. Biol. 15, 161.

Braun-Menendez, E., Fasciolo, J. C., Leloir, L. F. \& Muñoz, J. M. [1939]. Rev. Soc. argent. Biol. 15, 420.

Dicker, E. [1937]. C.R. Soc. Biol., Paris, 125, 1046.

Enger, R., Linder, F. \& Sarre, H. [1938]. Z. ges. exp. Med. 104, 18.

Fasciolo, J. C., Houssay, B. A. \& Taquini, A. C. [1938]. J. Physiol. 94, 281.

Goldblatt, H. [1937]. Ann. intern. Med. 11, 69.

Goldblatt, H., Lynch, J., Hanzal, R. F. \& Summerville, W. W. [1934]. J. exp. Med. 59, 347.

Grimson, K. S. [1939]. J. Physiol. 95, 45 P.

Hellerman, L. [1937]. Physiol. Rev. 17, 454.

Helmer, O. M. \& Page, I. H. [1939]. J. biol. Chem. 127, 757.

Hessel, G. [1938]. Klin. Wschr. 17, 843.

Houssay, B. A. \& Fasciolo, J. C. [1937a]. Bol. Acad. Med. B. Aires, p. 342.

Houssay, B. A. \& Fasciolo, J. C. [1937b]. Rev. Soc. argent. Biol. 13, 284. 
Houssay, B. A. \& Taquini, A. C. [1938a]. Rev. Soc. argent. Biol. 14, 5.

Houssay, B. A. \& Taquini, A. C. [1938b]. C.R. Soc. Biol., Paris, 128, 1125.

Kohlstaedt, K. G., Helmer, O. M. \& Page, I. H. [1938]. Proc. Soc. exp. Biol., N.Y., 39, 214.

Muñoz, J. M., Braun-Menendez, E., Fasciolo, J. C. \& Leloir, L. F. [1939]. Nature, Lond., 144, 980.

Pickering, G. W. \& Prinzmetal, M. [1938]. Clin. Sci. 3, 211.

Swingle, W. W., Taylor, A. R., Collings, W. D. \& Ways, H. W. [1939]. Amer. J. Physicl., $127,768$.

Tigerstedt, R. [1897]. XIIth Int. Congr. Med., Moscou, 2, sect. ח, 23.

Verney, E. B. \& Starling, E. H. [1922]. J. Physiol. 56, 353.

Verney, E. B. \& Vogt, M. [1938a]. J. Physiol. 93, 51P.

Verney. E. B. \& Vogt. M. [1938b]. Quart. J. exp. Physiol. 28, 253.

After this paper had been submitted for publication the report of Page \& Helmer, $J$. exp. Med., 1940, 71, 29, came to our notice. Their results are, in many respects, quite similar to those we have obtained. Further experiments have shown us that ischaemic kidneys secrete renin, hypertensin being subsequently produced in the blood, and also that the destruction of hypertensin by renin is due to impurities of the preparations. 